\title{
Cartografía sociopolítica de Venezuela: las novelas de Miguel Otero Silva
}

\author{
Sociopolitical cartography of Venezuela: the novels of Miguel Otero Silva
}

Carmen Becerra Suarez

Universidad de Vigo - Vigo, Espanha

\author{
$\diamond$
}

\begin{abstract}
Resumen: El artículo examina la narrativa ficcional del venezolano Otero Silva. En sus novelas, exceptuando las dos últimas, el autor dibuja una especie de mapa sociopolítico de la historia contemporánea de Venezuela, utilizando como material narrativo tanto sucesos que ha vivido como aquellos otros de los que ha sido testigo indirecto. Se trata de una escritura comprometida, de carácter histórico, que traza en cada una de las novelas una etapa del desarrollo nacional y busca constantemente la renovación formal.
\end{abstract}

Palabras clave: Novela; Historia; Biografismo; Venezuela; Otero Silva

\begin{abstract}
The article examines the fictional narrative of the Venezuelan Otero Silva. In his novels, except for the last two, the author created a kind of sociopolitical map of the contemporary history of Venezuela, using as narrative material both events he has lived and those he has been an indirect witness. It is a committed writing, historical in nature, that draws in each of the novels a stage of national development and constantly seeks formal renewal.
\end{abstract}

Keywords: Novel; History; Biography; Venezuela; Otero Silva

Parece evidente, a la luz de la bibliografía, que la literatura venezolana es, entre las latinoamericanas, la menos estudiada y conocida fuera del ámbito nacional; las causas son diversas, pero la crítica subraya como principal responsable el retraso con el que sus escritores se incorporan a las nuevas tendencias y explican el porqué:

\begin{abstract}
A la vigencia que en toda Hispanoamérica tuvo la literatura criollista hay que añadir en Venezuela el hecho de que uno de los grandes maestros del género sea, precisamente, Rómulo Gallegos. La publicación y el éxito de Doña Bárbara, en 1929, supuso no sólo la culminación de un ciclo (...) sino también su prolongación de manera excepcionalmente larga en su país de origen (DELGADO, 1984, p. 203).
\end{abstract}

Aunque fue Rómulo Gallegos el responsable de la acomodación de la literatura a la realidad venezolana al incorporarla a las grandes corrientes literarias mediante la utilización de una novelística ya superada en otros países, pero que en Venezuela, en razón de circunstancias políticosociales, no había sido posible desarrollar, es también la presencia de Gallegos la que frenó un desarrollo más universal de la literatura vernácula al recluir la suya, y la de muchos otros escritores, en los límites geográficos e imaginarios de un mundo que parece obtener su temática solamente en los lugares comunes y en el regionalismo. ${ }^{1}$

Tal vez este sea el motivo por el que, pese a la calidad e interés que atesoran las novelas del venezolano Miguel Otero Silva, ${ }^{2}$ su obra sigue siendo hoy bastante desconocida, fuera de las fronteras de su país, y escasamente atendida por la crítica. Pretendemos con este artículo colaborar en la difusión y conocimiento de la narrativa ficcional de este periodista y escritor, injustamente preterido, cuya lectura proporciona un

\footnotetext{
Ya Rafael di Prisco, en un artículo publicado en la revista Ínsula, en 1969, sostenía que "Es justamente el predominio de su figura y el mito que se comienza a construir en torno a Doña Bárbara, lo que frena el desarrollo fuera de nuestras fronteras de la novela vernácula y encierra a nuestros escritores en una estéril y emocional búsqueda" (1969, p.4).

2 Respecto a sus múltiples intereses y actividades desarrolladas, dice Efraín Subero: "En orden cronológico: poeta, político, periodista, novelista, otra vez poeta, otra vez periodista, empresario, humorista, otra vez político, otra vez novelista, crítico de arte, dramaturgo, viajero de lugares y experiencias, deportista, hasta crítico literario; todo eso ha sido progresivamente, y en ocasiones todo a la vez. Al fin y al cabo no existe un solo Miguel Otero Silva (Subero 1978, p. 13).
} 
retrato próximo y estremecedor de la realidad venezolana del siglo XX.

$\mathrm{Si}$, en términos generales, el análisis completo de una obra literaria no puede desvincularse del contexto en que nació, aquel en el que vivió su creador, tal separación es todavía más insostenible cuando el autor y su obra se funden de manera continua en un todo coherente, tanto en el mundo de la ficción como en el mundo real. Por ello, analizar en profundidad las novelas de Otero Silva requiere, en más de una ocasión, acudir a su biografía tan vinculada, por otro lado, a los avatares políticos y sociales venezolanos.

Otero Silva es autor de siete novelas, ${ }^{3}$ de ellas, las cinco primeras -Fiebre (1939), Casas muertas (1955), Oficina $n^{0} 1$ (1961), La muerte de Honorio (1963) у Cuando quiero llorar no lloro (1970)- responden, a juicio de Nieves Lorenzo,

[a] una voluntad manifiesta de crear un fresco ficcional de la historia de Venezuela, entendiendo ésta en sentido amplio como decurso de los distintos agentes (la política, el acontecer social, la cultura, etc.) que conforman una realidad nacional. (...) cada libro se corresponde con una etapa del desarrollo nacional (LORENZO, 1997, p. 8 y 10).

Partiendo de esta premisa, con la que coincidimos en su totalidad, es obvio que estudiar la novelística oteriana desde una perspectiva exclusivamente inmanentista daría lugar a resultados parciales e incompletos. No solo discurso literario contienen sus obras, en ellas existe además, y de manera evidente, retazos, sucesos, acontecimientos y personajes de la historia de Venezuela ficcionalizados, como veremos, mediante técnicas o recursos literarios, que es preciso tener en cuenta para explicar el verdadero sentido y valor de las mismas. ${ }^{4}$

Si consideramos, con Celia Fernández Prieto, que el rasgo más específico, también el más notorio, de los que caracterizan la novela histórica se revela en

la coexistencia en su mundo ficcional de personajes, acontecimientos y lugares inventados con personajes, acontecimientos y lugares procedentes de la historiografía, esto es, materiales que han sido codificados y documentados previamente a la escritura de la novela en otros discursos culturales a los que se reputa de históricos (FERNÁNDEZ PRIETO, 1998, p. 177),

podríamos calificar estas cinco novelas de Otero Silva con el adjetivo de históricas, dado que en ellas se mezclan

\footnotetext{
3 Lope de Aguirre, principe de la libertad (1979) y La piedra que era Cristo (1985) son los títulos de las dos novelas que completan la producción narrativa ficcional del autor.

4 A este respecto, sostiene Nieves Lorenzo: "lo que Otero Silva nos brinda es un diálogo entre el mundo novelesco y el correlato histórico, a través de unas premisas narrativas y de unas figuras literarias estrechamente vinculadas al contexto venezolano que más inquietaba al autor (Lorenzo, 1997, p. 10).
}

y combinan elementos procedentes de la imaginación del escritor con otros realmente acontecidos cuya documentación no supone dificultad alguna. Sin embargo, teniendo en cuenta que no son los personajes que protagonizan la historia quienes ostentan tal condición, sino el contexto en el que su vida se desarrolla y los hechos en ese tiempo acontecidos, preferimos hablar de novelas de carácter histórico. Con solo unos cuantos datos Otero Silva construye un mundo, con claras referencias extratextuales, que apela a la enciclopedia histórica y cultural del lector y le permite localizar los sucesos narrados.

Ahora bien, el carácter histórico de los elementos propuestos en la diégesis solo se mantiene si el destinatario posee el conocimiento del suceso o personajes históricos elegidos por el autor. En consecuencia, los elementos referenciales desempeñan un papel esencial en la construcción de este tipo de novela al proporcionar realismo, veracidad y coherencia al mundo narrativo en ellas creado, pero también en la conformación de una estrategia de lectura en la que el lector juega un papel determinante. Así, la continua transformación de los contextos culturales es una de las causas por las que el lector implícito previsto por el texto puede no coincidir con los lectores empíricos; es decir, las diferencias entre la enciclopedia cultural de uno y otros podría originar, como señala Celia Fernández Prieto, que "los lectores ya no estén en condiciones de reconocer a esas entidades como pertenecientes a la historiografía, y por tanto las entiendan como ficcionales, dejando sin activar su dimensión histórica" (1998, p. 183).

En las páginas que siguen, vamos a analizar la producción novelística del autor intentando trazar la línea que conforma su evolución.

Fiebre es el título de la primera novela escrita por Otero Silva. Se trata de la obra de un autor muy joven e inexperto ("comenzada con veinte años de edad y varios siglos de ignorancia a cuestas", dice en la primera frase del Prólogo a la edición de Seix Barral), ${ }^{5}$ que traslada a la literatura una experiencia vital. La novela, terminada en 1930, se publica en Caracas en 1939 con importantes correcciones:

Apañé las intentonas anteriores, logré apilarlas en la nueva coyuntura como doscientas páginas y las publiqué con empaque de libro, saliera sapo o rana, sin detenerme a corregirlas, sin mostrárselas previamente a un consejero idóneo. Así vino al mundo la primera edición de Fiebre en Caracas (Otero Silva, 1977a, p.9).

\footnotetext{
5 El párrafo final del Prólogo que Otero Silva escribe para la edición de la novela en Seix Barral (1977, p. 93) dice: “...escrita alrededor de 1931 por un estudiante de ingeniería (yo mismo), recién salido de un rudimentario bachillerato y sin haber ojeado todavía una sola página de Faulkner, ni de Joyce, ni de Kafka, ni siquiera de Proust. Tal vez sería más conveniente que no la leyera usted". Esta Introducción está fechada en Caracas, 1971
} 
Pero la edición definitiva no aparecerá hasta 1971. El autor posee entonces todas las claves de lo acontecido cuarenta años atrás, por ello reflexiona sobre lo escrito, revisa y corrige el texto y añade un extenso prólogo: ${ }^{6}$

Cuarenta años más tarde, releí mi lejano relato, y decidí (...) someterlo a un irremplazable tratamiento de cirugía (...). Eso sí, he mantenido intocados los personajes y la trama y también el estilo digamos "vanguardista" y la peculiaridad digamos "romántica" que eran los elementos peculiares de la generación del 28 (OTERO SILVA, 1977a, p. 10).

Dejando a un lado las sucesivas reescrituras a las que el autor sometió a su primera novela, ${ }^{7}$ en ella aborda el tema de la revolución estudiantil contra la dictadura de Juan Vicente Gómez, una revolución llevada a cabo por la llamada "generación del 28 ", grupo conformado por una base social muy heterogénea, al que Otero Silva pertenecía y en cuyas acciones participaba e incluso ideaba. ${ }^{9}$

La novela, o novela-reportaje, como la califica su autor, relata unos hechos muy próximos al momento de escritura y contiene numerosos datos autobiográficos, "no solamente individuales, sino autobiográficos de todo un grupo, de mis compañeros de lucha, de eso que se ha llamado 'generación del $28 \cdot{ }^{10}$ Las cosas que le suceden a Vidal Rojas en la primera fase del libro (...) me

\footnotetext{
6 Cinco años después, Fiebre es trasladada al cine bajo la dirección de Juan Santana y con guion de Salvador Garmendia. La película mantiene el mismo título que la novela de la que procede.

7 La edición original y la reedición del año 39 llevaban el subtítulo de Novela de la revolución venezolana, que explicitaba claramente el contenido y la intencionalidad autorial. Este subtítulo desaparece en el edición definitiva de 1971 .

8 A pesar del desarrollo económico de Venezuela a comienzos del siglo pasado, en nada se alteró la estructura política nacional (dictadura de Juan Vicente Gómez), y, además, favoreció la alternancia de las antiguas clases dominantes por las clases emergentes profundizando todavía más en la desigualdad social. Esta situación desencadenó en la segunda década del siglo en una proliferación de movimientos de protesta y de manifestaciones que convergen en la llamada "generación del 28", movimientos que eran contestados por el poder con la represión, la tortura y la muerte.

9 A los veinte años tiene que exiliarse, reside en Trinidad. Forma parte de un grupo armado que pretenden destituir a Gómez y, Desde Curaçao, invade el país por las costas del Coro; fracasado el intento por falta de apoyo interne, inicia un largo destierro que lo lleva de Curaçao a Europa, entre 1930 y 1036. Reside en España, Francia y Bélgica trabajando como periodista. Regresa a Venezuela en 1935, tras la muerte de Gómez, reanudando la lucha política a través del periodismo. Su beligerancia en la prensa que utiliza como instrumento de agitación popular le acarrea un nuevo destierro. El general López Contreras, ministro con Gómez y su sucesor en la presidencia del país, le expulsa en 1937, Reside en México y viaja por Estados Unidos, Cuba, Colombia y Panamá.

10 Entre los miembros de esta "generación”, en realidad, agrupación de estudiantes universitarios, podemos citar a Isaac Pardo, Pío Tamayo, Jóvito Villalba, Rómulo Betancourt, Guillermo Prince Lara y Jorge Saldivia Gil (los dos últimos figuran en la dedicatoria de la novela), entre otros.
}

sucedieron a mí en la vida real" (OTERO SILVA, 1977b, p. 44). ${ }^{11}$

Con lenguaje claro y sencillo y una retórica muy periodística, responsable de las reiteradas analogías que la crítica establece entre esta obra y la historia venezolana, la novela se divide en tres partes: 1) La Universidad (donde se detiene en la descripción de la corrupción políticosocial del período gomecista y la revolución estudiantil); 2) Montonera (en esta parte se habla de la guerrilla creada tras la rebelión: las acciones están descritas con un agudo sentido crítica y un marcado escepticismo); y 3) Fiebre (es una cruda descripción del campo de concentración de Palenque, lugar en el que de nuevo surgen, a pesar de todo y entremezclados, sentimientos de solidaridad, esperanza y amargura).

El protagonista, un estudiante llamado Vidal Rojas, representante de toda una generación, va recorriendo las tres etapas sufriendo una progresiva toma de conciencia que le conduce a la denuncia, por medio del monólogo, contra el régimen gomecista:

La política es para nosotros una obsesiva pesadilla, sin contornos precisos. Arriba está la gavilla de bandoleros que roba, atropella, tortura y asesina. Abajo hay tres millones de hombres que son robados, torturados, asesinados. (...). En nosotros cifra mucha gente -itanta gente!- su minúscula esperanza de redención. Y nosotros no poseemos más que una lumbre juvenil de rebeldía, apenas una lumbre. Somos dolorosamente ignorantes. Sabemos que existe algo, de lo cual tenemos un concepto libresco y casi abstracto, que se llama democracia (OTERO SILVA, 1977, p. 121).

Durante su estancia en el campo de Palenque, después de haber sido traicionado por la montonera, Vidal Rojas reflexiona sobre lo hecho, revisa su conciencia y el resultado lo traslada a una carta a sus compañeros; en ella explica la ausencia de criterio, el desorden, el fracaso por la inexperiencia, el cambio sufrido por todos ellos. Esta carta puede considerarse como el legado de su generación:

\begin{abstract}
Hermanos:
Yo sé que ustedes no son los mismos de 1928, como tampoco soy el mismo yo. Yo sé que el dolor los ha tallado, como me ha tallado a mí. Sé que en las tinieblas de los calabozos o bajo el sol de las carreteras hemos meditado y limado aquella ingenua ignorancia que nos nublaba la vista cuando nos lanzamos a la lucha (OTERO SILVA, 1977, p. 304). ${ }^{12}$
\end{abstract}

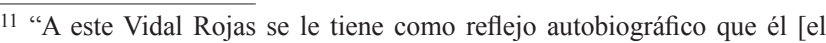
autor] en partes muy precisas reconoció y que en otras, o son datos fugaces de sus compañeros de generación, o complementos, como la agonía en Palenque, añadidos luego de los cuentos oídos a quienes pasaron, febriles, por los campos de trabajos forzados", dice Jesús Sanoja Hernández en un artículo publicado el 8 de septiembre de 1985, en la sección "Papel Literario", del diario El Nacional (periódico fundado por Miguel Otero Silva junto con su padre, Enrique Otero Vizcarrondo, en 1943).

12 Cito la novela por la edición en la editorial catalana, Seix Barral, en 1977.
} 
Pero las palabras de Vidal Rojas no son de desesperanza ni de frustración, bien al contrario, contienen un mensaje de fe en el futuro y de confianza en todos aquellos que harán posible una Venezuela mejor, más justa, más solidaria, más democrática; por eso la carta termina con una llamada a proseguir en la lucha: “ $¡ D e$ frente, hermanos, hacia el porvenir! Que el porvenir es nuestro aunque no hayamos de disfrutarlo en vida." (OTERO SILVA, 1977, p. 309).

Fiebre es un ejemplo claro de literatura de denuncia y de novela testimonial, refleja el pensamiento de la época en la que fue creada, pensamiento encarnado en personajes que aluden a una referencia extratextual, que representan las ideas y las acciones de un grupo, de una generación a la que el autor pertenece y de la que fue testigo y protagonista.

En 1954, después de muchos años entregado al periodismo, ${ }^{13}$ Otero Silva publica Casas muertas. ${ }^{14}$ La crítica la describe como el relato dramático de la desaparición, bajo el azote del paludismo, de un pueblo llamado Ortiz, situado en los llanos venezolanos.

Murieron muchos orticeños, cinco por día, quince por día, y fueron enterrados quién sabe dónde y quién sabe por quién. Otros, familias enteras, huyeron despavoridas, dejando la casa, los enseres, las matas del patio, el perro. Desde entonces adquirió definitivamente Ortiz ese atormentado aspecto de aldea abandonada, de ciudad aniquilada por un cataclismo, de misterioso escenario de una historia de aparecidos (OTERO SILVA, 1975, p. 36).

Sin embargo, a mi juicio, la definición es incompleta y falta de rigor al no considerar el contexto histórico en el que se desarrolla la historia. No podemos olvidar que en las primeras décadas del pasado siglo se desencadena, en la mayoría de los países latinoamericanos, un éxodo rural provocado por la decadencia o derrumbe del sistema agrícola latifundista al mismo tiempo que emergían nuevos sistemas económicos basados en la explotación de otros recursos; concretamente, en Venezuela, el factor dinamizador fue el petróleo.

La novela evidencia, es verdad, el abandono de Ortiz $^{15}$ ante el peligro real de la plaga, pero muestra

\footnotetext{
13 El 3 de agosto de 1943 comienza a circular en Venezuela la primera edición de El Nacional, diario que pronto será uno de los más importantes del país.

14 Obtuvo el Premio de Novela Arístides Rojas y, posteriormente, el Premio Nacional de Literatura. Cito por la edición en la editorial Seix Barral, en 1975.

15 El espacio en el que se ambienta la novela posee un referente real: Ortiz, pueblo del estado de Guárico, conocido como "La flor de los llanos". Ortiz pasó del auge y la prosperidad a convertirse en un pueblo deshabitado tras ser asolado por enfermedades endémicas, desgracia acompañada por la desidia de sus gobernantes. Pero no fui el único que sufrió esta experiencia, otros muchos pueblos venezolanos -Ospino, Calabozo, Guanare, Barinas- padecieron esye mismo drama.
}

también un desdén, una indiferencia de sus habitantes ante la destrucción, que no es identificable con una actitud fatalista. ${ }^{16} \mathrm{El}$ lector presencia la agonía de un pueblo que perdió su razón de ser, asiste a su desintegración ante el poderoso atractivo de la epidemia petrolífera que causa el nacimiento de las grandes poblados, en torno a los campos donde se extrae el petróleo; una nueva arcadia donde el oro negro va a generar suficiente riqueza como para importar, incluso, los alimentos.

El primer capítulo de la novela anuncia, desde el título -Entierro-, el problema al que se enfrentan los personajes, como relata la voz narradora que conduce el relato:

Esa mañana enterraron a Sebastián. El padre Pernía, que tanto afecto le profesó, se había puesto la sotana menos zurcida, la de visitar al Obispo, y el manteo y el bonete de las grandes ocasiones. Un entierro no era un acontecimiento inusitado en Ortiz. Por el contrario, ya el tanto arrastrarse de las alpargatas había extinguido definitivamente la hierba del camino que conducía al cementerio y los perros seguían con rutinaria mansedumbre a quienes cargaban la urna o les precedían señalando la ruta mil veces transitada. Pero había muerto Sebastián, cuya presencia fue un brioso pregón de vida en aquella aldea de muertos, y todos comprendían que su caída significaba la rendición plenaria del pueblo entero. Si no logró escapar de la muerte Sebastián, joven como la madrugada, fuerte como el río en invierno, voluntarioso como el toro sin castrar, no quedaba a los otros habitantes de Ortiz sino la resignada espera del acabamiento (OTERO SILVA, 1975, p. 7).

Ese es el futuro que a todos espera: muerte, destrucción. El medio rural, abandonado, se irá degradando al tiempo que se configura la nueva imagen de Venezuela, alrededor de incipientes y desordenados espacios semiurbanos. El viaje de Carmen Rosa, protagonista de Casas muertas, desde Ortiz (el mundo rural) a El Tigre (poblado petrolero en el que se sitúa la novela Oficina $N$ o 1), "pone en comunicación dos formas distintas de 'barbarie': de un lado, el llano, hostil, infinito, de formas anacrónicas; de otro, sólo un espejismo", en palabras de Nieves Lorenzo (1997, p. 109).

Sobre el proceso de escritura nos informa el novelista:

Para la preparación de Casas muertas me fui a Ortiz, que para entonces estaba al borde del derrumbe total, busque a los sobrevivientes de la época terrible (...). Entre estos interrogados estuvo una vieja maestra de escuela que me suministró los datos más valiosos (...) y que luego aparece en la novela bajo el nombre de la 'señorita Berenice' (OTERO SILVA, 1977, p.46).

\footnotetext{
${ }^{16}$ En el escenario orticeño el poder absoluto del dictador Gómez está representado por la figura del coronel Cubillos, jefe civil del pueblo.
} 
Desde el punto de vista formal, todavía se aprecia el importante peso de la herencia galleguista y de la novela regionalista (por ejemplo, en la ubicación en el llano venezolano, que aísla a sus habitantes de la civilización, o en la elaboración psicológica de los personajes), ${ }^{17} \sin$ embargo hay en esta novela otra serie de recursos que ponen de manifiesto una de las invariantes en la trayectoria del autor: la búsqueda constante de la renovación.

Entre esos recursos, a los que nos hemos referido arriba, tal vez el más destacado sea la utilización del tiempo, como medio de ordenación de los sucesos en una estructura circular; la finalidad que el autor persigue es contar el devenir histórico de Ortiz desde el florecimiento económico hasta un presente de tintes apocalípticos. El entierro de Sebastián sitúa la acción en el presente al comienzo del relato, a partir de ahí, capítulos IIXI, el narrador y los recuerdos de algunos personajes (Hermelinda y Cartaya) nos conducen al pasado de Ortiz, una ciudad llanera de construcciones españolas, llena de alegría, baile, música y animación; sobre ese ambiente se evoca la infancia y adolescencia de Carmen Rosa, cuya familia, como el pueblo en que viven, ha transitado de la riqueza a la precariedad y la ruina, a consecuencia del declive de la agricultura y la presión de la economía del petróleo. El último párrafo del capítulo XI, da fin a la retrospección y nos devuelve de nuevo al presente:

El padre Pernía bendijo el cadáver y le cubrió la faz amarilla. Carmen Rosa rompió a llorar sin trabas, refugiada la frente entre las manos, curvada sobre la mesa donde la lámpara de la Virgen del Carmen consumía sus últimas gotas de querosén. Así se mantuvo horas enteras... (...). Solo levantó el rostro cuando en la torre de la iglesia comenzaron a doblar las campanas (OTERO SILVA, 1975, p. 128).

Por fin, el último capítulo, el XII, funciona como lazo de unión de esta novela con la que unos años más tarde, será el siguiente título de la novelística oteriana, Oficina № 1. En él, Carmen Rosa abandona el pueblo camino de la región oriental, donde se instalan los primeros poblados nacidos alrededor del petróleo, en busca de un mejor futuro:

Carmen Rosa no estaba dispuesta a derrumbarse con las últimas casas de Ortiz. Tras meditarlo largamente, se lo dijo a doña Carmelita una mañana:

- nos vamos a Oriente mamá (...)

Un día de mayo abandonaron las casas muertas... (OTERO SILVA, 1975, p. 134 y 140).

La novela contiene además un capítulo cuyo contenido resulta de especial interés. Estamos aludiendo al

\footnotetext{
17 Para Carlos Pacheco, Casas muertas "representa un logro estético como manifestación de un regionalismo depurado y poetizado" (1994, p. 191)
}

capítulo VI, "Este es el camino de Palenque", que vincula temporal y políticamente ${ }^{18}$ a Ortiz y sus habitantes con el grupo protagonista de Fiebre, muchos de los cuales, como sabemos, terminan sus días en el campo de concentración de Palenque:

Un mediodía de noviembre, era domingo por cierto, se detuvo un autobús en Ortiz. (...) Los estudiantes ignoraban la meta de aquel autobús amarillo que corría locamente con ellos adentro. (...) Tan solo vislumbraron el destino que les aguardaba cuando el autobús abandonó la carretera que iba en busca del mar y torció bruscamente hacia los Llanos (OTERO SILVA, 1975, p. 77, 78 y 79).

La actitud de los orticeños ante el paso del autobús es de sorpresa e ignorancia, hecho que pone de relieve el aislamiento de los pueblos llaneros y su desconocimiento de lo que en la lejana Caracas sucede, solo el Padre Pernía es consciente del trágico destino de aquellos jóvenes "Por el camino que se fueron, no queda sino Palenque, que es la muerte" (OTERO SILVA, 1975, p. 81).

Oficina $N^{\circ} 1$, tercera de las novelas del autor, se publica en la editorial Losada, Argentina, en 1961. Narra el nacimiento de un campamento petrolero en torno al pozo llamado Oficina $\mathrm{n}$ 1 , que día a día va transformándose en una poblado petrolero, aún sin nombre, que se corresponde con la ciudad real de El Tigre (estado de Anzoátegui). Otero Silva, que define su novela como "la historia de una ciudad mal nacida, parida sin comadrona por la explotación petrolífera, con características anárquicas de campamento, con innegables rasgos de frustración" (Otero Silva, 1977b, p. 47), ${ }^{19}$ describe un escenario poblado por los tipos humanos más dispares y heterogéneos que configuran la nueva imagen de Venezuela. A ese territorio babel, a la tierra prometida, al oriente donde les aguarda el porvenir, llegan Carmen Rosa, su madre, doña Carmelita, y Olegario, los personajes que habíamos dejado en Casas muertas abandonado Ortiz, después de recorrer varios cientos de kilómetros y pasar por Santa María de Ipire, Pariaguán y Valle La Pascua.

De nuevo Otero Silva busca en la realidad el material necesario para sus ficciones:

\begin{abstract}
Me desterré a la ciudad petrolera de El Tigre, indagué quiénes habían sido los pioneros de los primeros campamentos, hablé con quienes tenían mayor número de cosas que contar, visité con ellos los lupanares abandonados, las cantinas derrumbadas, las viejas construcciones descabelladas (OTERO SILVA, 1977b, p. 46).
\end{abstract}

\footnotetext{
${ }^{18}$ La acción se sitúa en 1929, durante la dictadura de Juan Vicente Gómez.

${ }^{19} \mathrm{La}$ crítica ha agrupado las narraciones (cuentos o novelas) que se desarrollan en este escenario bajo la denominación de "novelas del petróleo", a pesar de que la mayor parte de los autores que han abordado este tema lo han hecho utilizando la narrativa breve.
} 
El período temporal abarcado por la historia en Oficina $N$ o 1 discurre entre los años finales de la dictadura de Gómez, el gobierno de Eleazar López Contreras (19351941), que le sucede, y el período democrático de Isaías Medina Angarita (1941-1945). En el penúltimo párrafo de la novela, la inscripción de una placa colocada en el antiguo Pozo Oficina $\mathrm{n}^{-} \mathbf{1}$, proporciona la fecha exacta para datar el relato:

\section{SE INICIÓ LA PERFORACIÓN DE ESTE POZO OFICINA № 1 EL 23 DE FEBRERO DE 1933 Y FUE EL PRIMER POZO PERFORADO EN LOS LLANOS DEL ESTE DE VENEZUELA. FUE COMPLETADO EL 16 DE JULIO DE 1937 A UNA PROFUNDIDAD FINAL DE 6.184 PIES (OTERO SILVA, 1975, p. 233; mayúscula en el texto).}

En lo que se refiere a aspectos formales, el discurso novelesco aparece traspasado por la continua introducción o referencia a acontecimientos reales que sirven para fijar la cronología de la historia narrada. Así, por ejemplo, se habla de la muerte de Gómez (1935), o de la gran huelga petrolera de estado de Zulia (1936), donde se crea el primer sindicato petrolero venezolano; se incorporan además transcripciones de noticias radiofónicas sobre el final de la Guerra Civil española y el comienzo de la Segunda Guerra Mundial. Todos estos datos proporcionan a la obra realismo y credibilidad.

La novela fue recibida por la crítica con diversidad de juicios, para unos es la peor de su autor, mientras que para otros es una obra imprescindible. A nuestro parecer, Oficina $N^{o} 1$ descubre la intención del escritor de lograr una nueva estética; entreverada por pinceladas de lirismo ("luna inmensa y deforme, calabaza de luz, vientre desnudo de un niño de fuego" (p. 233), es una novela de difícil estructura, a veces caótica y laberíntica como el mundo que retrata, narrada por muchas voces, en donde el protagonismo de Carmen Rosa se va diluyendo ante la emergencia del verdadero actor principal de la novela: el petróleo y la ciudad en construcción que, alrededor de su extracción, se va creando. Nieves Lorenzo observa en esta novela la construcción de un microcosmos en el que se enfrentan o contrastan dos culturas, dos modos de vida:

[el autor] demuestra en Oficina $n^{\circ} 1$ que con el establecimiento del sistema económico petrolero, más que una simple y poderosa implantación de nuevas formas culturales - que de hecho se dieron-, se ponen en contacto dos modelos de cultura: uno foráneo, moderno, norteamericanizado, y otro interno, tradicional, primitivo, criollo. Pero además, para hacer frente a la hegemonía cultural del primer paradigma perviven las tradiciones, los ritos o ceremonias culturales criollas (LORENZO, 1997, p. 384)
Su cuarta novela, La muerte de Honorio aparece en 1963, continuando la secuencia iniciada en su novelística anterior y la progresión histórica de su narrativa, acompañamos al ciudadano venezolano ahora inmerso en la gran urbe y sometido a la ferocidad de la dictadura. En un alegato contra la tortura, el autor presenta a cinco luchadores que, como tantos otros compatriotas, son encarcelados y maltratados, de manera cruel e inhumana, bajo el régimen del dictador Pérez Jiménez. En referencia al tiempo que comprende la historia narrada, José Ramón Medina precisa que:

La muerte de Honorio se sitúa exactamente en los ocho o diez meses que precedieron a la caída de Pérez Jiménez, en 1958; pero en el recuerdo de sus protagonistas nos lleva hasta mucho más atrás, y nos pone al tanto de mucho de lo ocurrido en Venezuela desde el derrocamiento del gobierno democrático de Isaías Medina Angarita, en 1945 (MEDINA, 1985, XXI).

Otero Silva utiliza aquí formas narrativas innovadoras que lo incorporan a las últimas corrientes europeas. El diseño de la novela responde a una estructura dividida en dos partes llamadas "Cuadernos". En el primero, titulado "Cinco que no hablaron", se subdivide en seis partes. Comienza narrando el traslado de cinco presos desde la cárcel modelo de Caracas hasta la Cárcel Nueva de Ciudad Bolívar. Una vez allí se suceden las cinco historias, encabezadas por la profesión de su protagonista ("El tenedor de libros", "El periodista", "El médico", "El capitán" y "El barbero"), historias en las que describen a sus compañeros de celda las torturas que han recibido mientras, gracias al monólogo interior, conocemos sus vidas, su ideología y sus frustraciones. En el segundo Cuaderno, titulado "Honorio y su muerte", escrito a modo de diario, se narra la solidaridad entre los cinco presos en torno a la figura inexistente de un niño -Honorio-, supuesto hijo del barbero que poco a poco se irá convirtiendo en el hijo simbólico de todos ellos y cuya 'muerte' les dejará sumidos en la más completa desesperanza.

Si bien el autor confiesa no haber tratado de plasmar simbología alguna en el personaje del niño, y afirma que dicha figura surgió de una historia contada por un barbero, ${ }^{20}$ no es difícil aventurar que Honorio simboliza la unidad del pueblo venezolano solo ante la desdicha; Honorio podría representar la Venezuela añorada antes del sufrimiento. Imagen que después el escepticismo se encarga de descomponer.

Como sucede en otras obras, también aquí sale a la luz la faceta periodística de su creador. La novela

\footnotetext{
20 "No fue un mensaje elaborado como símbolo unitario sino una historia inspirada en un relato que me hizo un barbero de Dueca" (OTERO SILVA, 1997b, p. 47)
} 
es, en última instancia, un reportaje ya que denuncia los padecimientos sufridos por los presos en las cárceles de Pérez Jiménez. Sostener que la literatura de este autor es literatura de denuncia no es difícil de probar, será suficiente con conocer la realidad sociopolítica venezolana del siglo XX y luego leer sus novelas, para las que el propio escritor reclama dicha calificación:

Todas mis novelas son literatura de denuncia. Fiebre es una denuncia del sistema y del terror gomecista; Casas muertas es la denuncia del mal morir de una ciudad aniquilada por el paludismo, el gamonalismo ${ }^{21}$ y las guerras civiles; Oficina $N$ o 1 es la denuncia del mal nacer de una ciudad al rescoldo de la explotación minera imperialista; La muerte de Honorio es la denuncia del despotismo de Pérez Jiménez y de sus monstruosos procedimientos. Pero la naturaleza denunciante de estos libros no implica que se les tome por carteles políticos, literatura panfletaria, "realismo socialista", o como se llame tal tendencia. He procurado honestamente que mis denuncias conserven dignidad de obras artísticas, linaje de creación literaria (OTERO SILVA, 1977b, p. 54-55).

En 1970, publica Cuando quiero llorar no lloro, ${ }^{22}$ última de las novelas de las que nos ocuparemos en este trabajo y, tal vez, una de sus mejores creaciones. El material narrativo, que conforma una arquitectura bastante compleja, se distribuye en dos partes claramente diferenciadas cuyo nexo de unión es la palabra 'mártir', en su acepción de 'persona que da testimonio de...'. La primera parte, contiene la narración del último día de vida de los mártires Severo, Severiano, Carpóforo y Vctorino cuya muerte se debe a su voluntad de adjurar de su fe habiéndoles tocado vivir en la época de persecución a los cristianos del emperador romano Diocleciano, La segunda parte, cuenta la vida de tres jóvenes caraqueños -Victorino Pérez, Victorino Perdomo y Victorino Peraltaque tienen en común, además del nombre propio, el haber nacido el mismo día del mismo año: el 8 de noviembre de 1948, fiesta cristiana de los santos Severo, Severiano, Carpóforo y Victorino; el nombre de este último se les impone a los tres recién nacidos. Hasta ahí las semejanzas y desde ahí las diferencias generadas por su pertenencia a clases sociales diferentes. El tratamiento de cada personaje y las técnicas utilizadas para narrar su historia es también diferente; la caracterización de cada uno de ellos obtiene su valor, precisamente, del contraste con los otros dos, actuando así cada historia como contrapunto de la anterior y la siguiente.

\footnotetext{
${ }^{21}$ Se denomina así al poder ejercido por los hacendados, los gamonales. Gamonalismo es, por tanto, el caciquismo rural.

${ }^{22}$ La novela se convirtió desde su publicación en uno de los más importantes éxitos editoriales de Venezuela
}

Pero entremos un poco más en detalle en el análisis de esta novela. La narración de sus vidas se realiza de manera discontinua y alternada para confluir al final en otro punto común localizado en el Epílogo cuyo título es el mismo que el de la novela: el entierro de los tres jóvenes en el mismo cementerio, aunque en zonas distintas y el mismo día: el 9 de noviembre de 1966. Respecto a este punto, señala Carlos Pacheco:

Este esqueleto estructural de tres líneas accionales centradas en los tres Victorinos y entrelazadas a lo largo del relato, permite la gradual construcción ficcional de los tres "mundos" respectivos, alcanzando así una imagen panorámica indudablemente más amplia y compleja (aunque todavía algo esquemática por momentos) de Ia sociedad venezolana de la época (PACHECO, 1994, p. 192).

La forma con la que está escrita la novela es muy innovadora: absoluta falta de acatamiento a las normas académicas de puntuación, frases sin terminar, jocosa falta de respeto al relato histórico, introducción continua del monólogo interior en sus variadas formas, presencia explicita de una voz que podemos identificar con la del autor, presencia tímida de formulaciones metaficcionales, etc., todos estos recursos formales la convierten en una novela vanguardista y renovadora.

En lo que al fondo de la obra se refiere, nos encontramos en la gran ciudad $\mathrm{y}$, en su interior, desaparecida la dictadura, la visión del país se muestra con toda su crudeza: las terribles injusticias sociales, la soledad asfixiante del hombre, la desigualdad social,..., una visión que no es otra cosa que un grito de alarma. Esas condiciones sociales se erigen en la circunstancia que configura, mueve, transforma y crea los valores o sin-valores de los personajes y los conduce como sísifos absurdos hacia un destino funesto.

Las diferencias entre los personajes son notorias, pero existen, sin embargo, ciertos puntos de contacto, procedentes siempre del exterior, que los une y relaciona. Tal es el caso del espacio en el que se desarrolla su breve vida, Caracas, espacio que actúa como elemento opresor para todos ellos, si bien no es equiparable el grado de conciencia que poseen de este hecho. Así, Victorino Pérez, tras las rejas de una cárcel, siente la angustia de su privación de libertad física, mientras que lo que oprime a Victorino Perdomo es la carencia de las libertades y derechos humanos que las estructuras sociopolíticas de su país representan. Es Victorino Peralta el único que aparentemente se siente libre en su espacio vital, o el que encubre su consciencia de oprimido en favor de intereses personales pragmáticos.

Esa consciencia de oprimidos, aunque a distinto nivel, origina que Pérez y Perdomo parezcan vinculados 
por la vivencia obsesiva del tiempo; ambos intentan huir, pero de distinto modo, de ese espacio que les somete, para ello es necesario calcular, controlar, apurar el tiempo segundo a segundo con el fin de evitar ser destruido. Sin embargo, hay también en este principio de unión un punto de discordia: para Perdomo, el tiempo equivale a transformación, a lucha contra un sistema hostil; se trata de un tiempo de rebeldía en el que hay que llevar a cabo lo que la generación precedente, como su padre, no tuvo arrestos o posibilidades de realizar. Para Pérez, en cambio, el tiempo lo es de fuga, de una huida que no sabe cuándo empezó; Pérez es consciente de que su destino es huir, robar, matar, y huir nuevamente de un castigo que considera natural.

Muy otro es el significado del tiempo para Peralta: almacén de recuerdos en el que está siempre presente el miedo y fundamentalmente el riesgo. Rodeado desde la cuna de seguridad, mimos y halagos repudia a su familia y a la sociedad, y busca con ahínco - aún sin saberlo- la autodestrucción, acercándose cada día más a la muerte a través de la imagen que de ella prefigura el peligro.

La novela es una sátira del poder político que, a juicio de José Ramón Medina,

presenta el cuadro dramático de la violencia que imperó en Venezuela durante casi toda la década de los años sesenta, y que hizo de la juventud su principal víctima, trágicamente signada, o bien por la agitación guerrillera de los grupos de izquierda que se empeñaban en derrocar el poder constituido para establecer un régimen socialista, o bien por la delincuencia marginal, o por la delincuencia patotera que durante mucho tiempo imperó entre jóvenes de familias pudientes (MEDINA, 1985, XXII).

En suma, cualquiera que se aproxime a la biografía de Miguel Otero Silva comprobará inmediatamente los indisolubles y múltiples lazos que lo ligan al discurrir social, político y cultural de la Venezuela del siglo XX. Las razones que justifican este férreo vínculo entre autor y país se apoyan, sin duda, en su multifacetismo (su larga actividad como escritor y periodística, su labor como crítico arte, su faceta como político), pero también se deben a su irrenunciable inconformismo. El análisis de una parte del corpus novelístico oteriano revela un proceso constante y consciente de evolución formal. A medida que avanza en su narrativa, además del perfeccionamiento estilístico, el autor va gradualmente enmendando errores al tiempo que toma conciencia del acto creador. Desde su primera obra de ficción -Fiebre- hasta la última aquí
estudiada-Cuando quiero llorar no lloro-, las novelas de Otero Silva, al margen de transformaciones estéticas que transitan desde la intención testimonial al realismo crítico, trazan una cartografía sociopolítica de la Venezuela del siglo XX, basada en la ficcionalización de una serie de sucesos vividos, a veces en primera persona, por un autor que ha sido siempre un testigo interesado, despierto e implicado. Por todo ello suscribimos las palabras de Carlos Pacheco cuando afirma que los protagonistas oterianos, "sin llegar a ser nunca paradigmas moralizantes (...) se levantan como símbolos vivientes de una propuesta ideológica perseverante, de una consistente dirección ética y humana, dentro de una trayectoria literaria de indudable validez estética" (PACHECO, 1994, p. 197).

\section{Referencias}

DELGADO, Luisa Elena. Miguel Otero Silva y la nueva novela venezolana. Anales de Literatura Hispanoamericana. 1984. Vol. 13, p. 203-207.

DI PRISCO, Rafael. Conciencia e inconsciencia en la novela venezolana. Ínsula, p. 272-273, 1969.

FERNÁNDEZ PRIETO, Celia. Historia y novela: Poética de la novela histórica. Navarra: Eunsa, 1998. (Anejos de Rilce, 23).

LORENZO, Nieves María Concepción. La fabulación de la realidad en la narrativa de Miguel Otero Silva. Diss. Universidad de La Laguna, 1997.

MEDINA, José Ramón. "Prólogo" a la edición Casas muertas y Lope de Aguirre, príncipe de la libertad. Caracas: Fundación Biblioteca Ayacucho, 1985.

OTERO SILVA, Miguel. Oficina № 1. Barcelona: Seix Barral, 1975.

OTERO SILVA, Miguel. "Prólogo" a Fiebre, Barcelona: Seix Barral, 1977a.

OTERO SILVA, Miguel. "Prueba oral de un novelista". In: Prosa completa. Barcelona: Seix Barral, 1977b.

PACHECO, Carlos. Retrospectiva crítica de Miguel Otero Silva. Revista Iberoamericana, v. LX, n. 166-167, p. 185-197, 1994.

SANOJA HERNÁNDEZ, Jesús. Voces secretas en la obra de Otero Silva, en "Papel Literario, El Nacional, Caracas, 8 de septiembre de 1985, p. 7.

SUERO, Efrain. Cercania de Miguel Otero Silva. Caracas: Editorial Arte, 1978.

Recebido: 20 de abril de 2017

Aprovado: 20 de junho de 2017

Contato:

Carmen Becerra Suarez<cbecerra@uvigo.es> 